\title{
EEG monitoring during endovascular treatment for carotid obstruction: a case report
}

Cavalcante S.L.F. ${ }^{1}$, Nunes R.R. ${ }^{1}$, Lopes C.G. ${ }^{2}$, Fernandes M.B.C. ${ }^{1}$, Sales A.J.B. ${ }^{1}$, Lima F.B. ${ }^{1}$

${ }^{1}$ Hospital Geral de Fortaleza, Dept of Anaesthesiology, Fortaleza, Brazil,

${ }^{2}$ Hospital Sao Carlos, Dept of Anaesthesiology, Fortaleza, Brazil

Background: Proper brain functioning depends on the balance between neuronal metabolism and cerebral circulation. Carotid obstruction causes the loss of this balance, and cerebral distress.

Electroencephalographic monitoring using BIS generates timely information on the depth of anesthesia and the state of cerebral hypoperfusion, quantified as suppression rate (SR). In this case report we describe EEG changes in a patient with carotid obstruction and show the importance of EEG monitoring during endovascular treatment.

Case report: A 59-year-old hypertense and diabetic man has a history of 5 episodes of transient ischemic attack. Arteriography of the carotids showed $100 \%$ obstruction on the left side and $95 \%$ on the right side, with indication for endovascular treatment with stenting of the right carotid (RC). Upon admission, the patient was awake, responsive to verbal commands, despite attention deficit. Initial findings: $B P=117 \times 78$ $\mathrm{mmHg}, \mathrm{HR}=55 \mathrm{bpm}, \mathrm{BIS}=75, \mathrm{BSR}=4 \%$, and slow EEG with low amplitudes, compatible with neuronal distress. Dexmedetomidine i.v $\left(1 \mu \mathrm{g} \cdot \mathrm{kg}^{-1}\right.$ for $10 \mathrm{~min}$, then $\left.0.5 \mu \mathrm{g} \cdot \mathrm{kg}^{-1} \cdot \mathrm{h}^{-1}\right)$ and fentanyl i.v. $(100 \mu \mathrm{g})$ were infused. A filter and a stent were placed in RC. Before

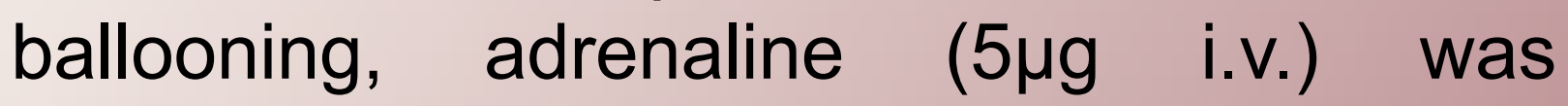
administered and findings were: $\mathrm{HR}=84 \mathrm{bpm}$, $\mathrm{BP}=168 \times 93 \mathrm{mmHg}, \mathrm{BIS}=75, \mathrm{BSR}=4 \%$.
After ballooning, $\mathrm{BIS}=73-74$ and $\mathrm{BSR}=0$. The neurological status was satisfactory and the $R C$ was well perfused (BIS $=90$ and $B S R=0$ ). After a few minutes, BSR was again $4 \%$ and a new image revealed vasospasm in RC. The filter was removed, resulting in BIS=90 and $B S R=0$. Upon emergence, the patient was oriented, without neurological deficits.

Discussion: Cerebral monitoring during endovascular treatment for carotid obstruction made it possible to observe electrical changes (burst suppression) due to compromised brain perfusion.
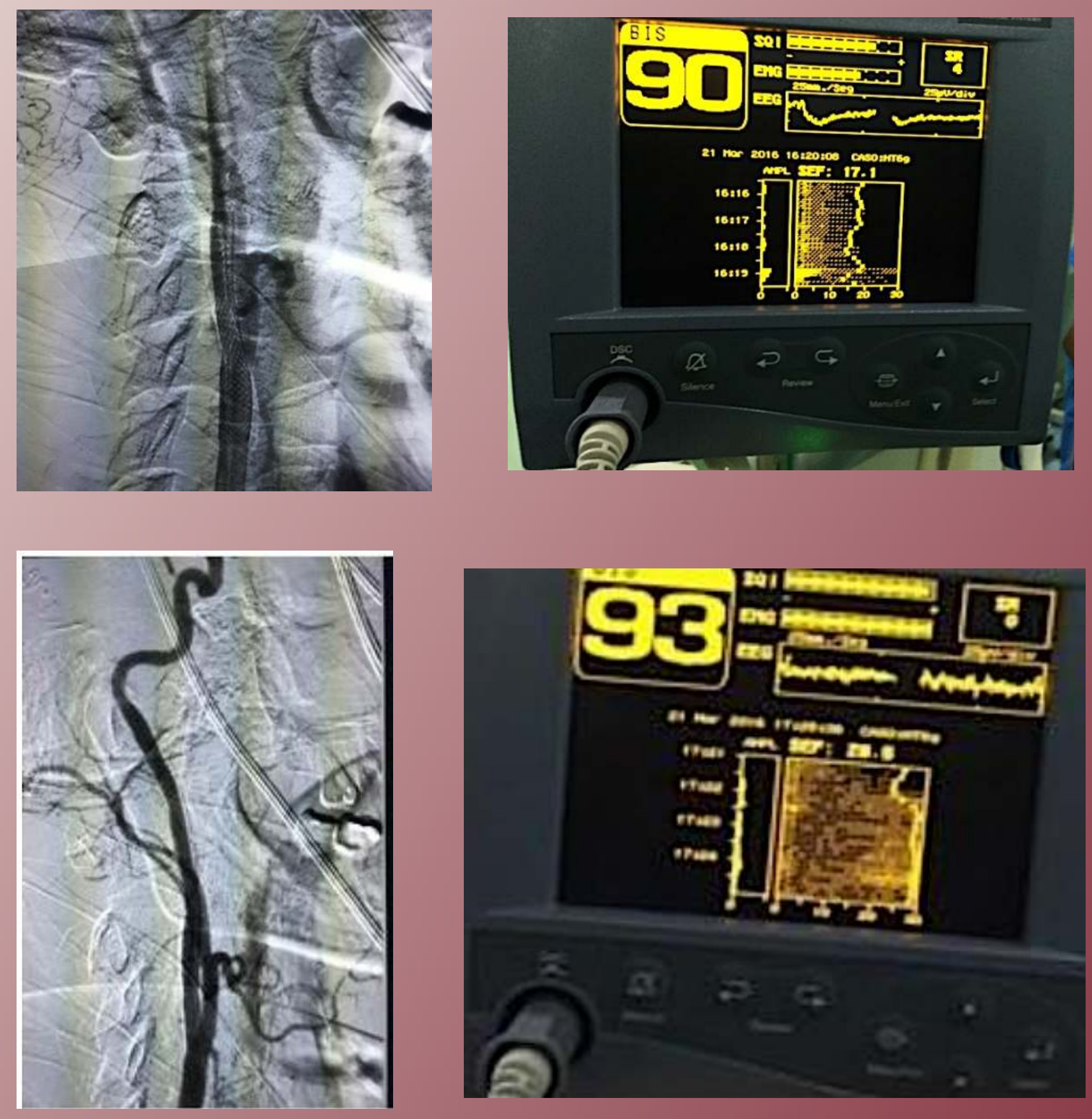

Reference: 1. Li J, Shalabi A, Ji F, Meng L. Monitoring cerebral ischemia during carotid endarterectomy and stenting. $\mathrm{J}$ Biomed Res. 2017, 31:00-00 in press. 